Research Article

\title{
Cyclophilin A Protects Cardiomyocytes against Hypoxia/Reoxygenation-Induced Apoptosis via the AKT/Nox2 Pathway
}

\author{
Fuyu Cheng, ${ }^{1}$ Wei Yuan $\mathbb{D}^{1},{ }^{1}$ Mengfei Cao, ${ }^{1}$ Rui Chen, ${ }^{1}$ Xiuli $W u,{ }^{2}$ and Jinchuan Yan ${ }^{1}$ \\ ${ }^{1}$ Department of Cardiology, Affiliated Hospital of Jiangsu University, Zhenjiang, Jiangsu Province, China \\ ${ }^{2}$ Department of Cardiology, Jurong Pepole's Hospital, Jurong, Jiangsu Province, China \\ Correspondence should be addressed to Wei Yuan; yuanwei1@medmail.com.cn
}

Received 19 December 2018; Revised 11 March 2019; Accepted 27 March 2019; Published 28 April 2019

Academic Editor: Roberto Carnevale

Copyright () 2019 Fuyu Cheng et al. This is an open access article distributed under the Creative Commons Attribution License, which permits unrestricted use, distribution, and reproduction in any medium, provided the original work is properly cited.

\begin{abstract}
Hypoxia/reoxygenation (H/R) accelerates the process of cardiomyocyte apoptosis during ischemia-reperfusion. Excessive reactive oxygen species (ROS) are a critical driver of oxidative stress injury. Cyclophilin A (CyPA) is a major ROS-induced factor in atherosclerosis. There is a positive feedback mechanism between CyPA and ROS, which enables the oxidative stress response to continue and expand. However, it is unclear whether this positive feedback mechanism exists in cardiomyocytes. Through western blotting and flow cytometric assays and TUNEL assay, we found that CyPA inhibited the apoptosis of H9c2 cardiomyocytes under H/R conditions. By dihydroethidium (DHE) staining and electron spin resonance (ESR) assays, we demonstrated that CyPA reduced ROS production and suppressed $\mathrm{O}_{2}{ }^{-}$production dependent on reduced nicotinamide adenine dinucleotide phosphate (NADPH) oxidase. By western blotting, we showed that CyPA inhibited the expression of NADPH oxidase 2 (Nox2) protein by the AKT pathway. Through confocal microscopy assay, we found that CyPA reduced the expression of Nox 2 membrane-bound subunits. The current study shows that a positive feedback mechanism does not exist in $\mathrm{H} 9 \mathrm{c} 2$ cardiomyoblasts. CyPA protects $\mathrm{H} 9 \mathrm{c} 2$ cardiomyoblasts against H/R-induced apoptosis via the AKT/Nox2 pathway. This could be a potential target for ischemia-reperfusion injury therapy.
\end{abstract}

\section{Introduction}

In ischemia-reperfusion injury, the main cause of injury to the tissue is not the ischemia itself; the injury occurs after the recovery of the blood supply and is caused at least in part by excessive reactive oxygen species (ROS) attacking the cells in the tissue that regains its blood supply. Cyclophilin A ( $\mathrm{CyPA})$ is involved in the process of ischemia-reperfusion in tissues and exhibits different effects in a variety of cells. CyPA is a highly conserved protein in cells, which belongs to the cyclophilin family [1]. CyPA was the first member of the cyclophilin family to be discovered and is mainly located in the cytoplasm. It is widely distributed in almost all tissues $[2,3]$. CyPA is classified into a variety of proteins termed foldases due to its enzymatic properties, its role in protein folding, and its cellular localization [4]. It is necessary for protein folding because of its enzymatic peptidyl prolyl cis-/ trans-isomerase (PPIase) activity [5]. In addition to its role in protein folding, CyPA has been demonstrated to have a variety of functions, such as intracellular protein trafficking $[6,7]$, mitochondrial function $[8,9]$, maintenance of multiprotein complex stability [6], and pre-mRNA processing [10].

Although CyPA was once considered to be an intracellular protein, in recent years, it has been found that CyPA can be secreted outside the cell under conditions of inflammatory stimuli and oxidative stress $[11,12]$. Recent studies have indicated that CyPA plays an irreplaceable role in the transport of NADPH oxidase (Nox) enzymes such as p47phox [13]. Recent studies have shown that Nox enzymes play a key role in tissues and organs during I/R $[14,15]$. The Noxes are also known to cause vascular smooth muscle cell (VSMC) proliferation and vascular disease development [16]. In VSMCs, CyPA and Nox enzymes synergistically amplify 
ROS formation due to the activation of other oxidase systems by ROS produced by Nox enzymes [11], resulting in increased oxidative stress [17]. Although little is known about the role of CyPA in cardiomyocytes stimulated by hypoxia/reoxygenation $(\mathrm{H} / \mathrm{R})$, studies have suggested that the antioxidant activity of CyPA protects cancer cells against cell death under hypoxic conditions $[18,19]$. The research of Boulos' team also suggests that extracellular CyPA can increase neuronal tolerance to oxidative stress [20]. Although the role of CyPA in cardiomyocyte apoptosis stimulated by $\mathrm{H} / \mathrm{R}$ is still unclear, several reports have shown that CyPA is released from cardiomyocytes to cope with $H / R$, possibly protecting cardiomyocytes against oxidative stress-induced apoptosis [21]. All these reports indicate that CyPA may be critical for the antioxidant capacity of cardiomyocytes. In this study, we show that CyPA protects H9c2 cells against $\mathrm{H} / \mathrm{R}$-induced apoptosis, at least in part due to inhibition of $\mathrm{NADPH}$ oxidase activity.

\section{Materials and Methods}

2.1. Cell Culture and Hypoxia/Reoxygenation. The rat myocardial cell line H9c2 was purchased from the Cell Bank of the Shanghai Institutes for Biological Sciences, Chinese Academy of Sciences. H9c2 cardiomyocytes were grown in DMEM (Gibco, NY, USA) supplemented with $10 \%$ fetal bovine serum (FBS; Wisent, Montreal, Canada), 100 units/mL penicillin, and 100 units/mL streptomycin at $37^{\circ} \mathrm{C}$ with $5 \% \mathrm{CO}_{2}$ in a humidified atmosphere. $\mathrm{H} / \mathrm{R}$ conditions were produced by placing cells in a H/R chamber $(1 \%$ $\mathrm{O}_{2}, 94 \% \mathrm{~N}_{2}$, and $5 \% \mathrm{CO}_{2}$ ) for a specific period of time.

CyPA preparation: CyPA (Abcam, ab86219) was dissolved in DMEM for the treatment of cells.

GSK690693 preparation: GSK690693 (MCE, HY-10249) is a novel Akt kinase inhibitor. GSK690693 was dissolved in dimethyl sulfoxide (DMSO) at a concentration of $10 \mu \mathrm{M}$ before use.

GSK2795039 preparation: GSK2795039 (MCE, HY18950 ) is a NADPH oxidase 2 inhibitor. GSK2795039 was dissolved in DMSO at a concentration of $10 \mu \mathrm{M}$ before cell treatment.

2.2. Western Blot Analysis. Protein expression levels of BAX, Bcl-2, caspase 3, Nox1, Nox2, Nox4, AKT, p-AKT-Ser473, and $\beta$-actin were analyzed by western blotting as described above [22]. In brief, $\mathrm{H} 9 \mathrm{c} 2$ cells were washed twice with phosphate-buffered saline (PBS) and lysed in lysis buffer for $30 \mathrm{~min}$ at $4^{\circ} \mathrm{C}$. Cell lysates were centrifuged at $12,000 \mathrm{rpm}$ for $15 \mathrm{~min}$ at $4^{\circ} \mathrm{C}$. The protein concentration was measured with the BCA protein assay reagent kit (Thermo Fisher, 23227). After boiling for $5 \mathrm{~min}$ at $95^{\circ} \mathrm{C}$ in a $5 \times$ loading buffer, an equal amount of protein was separated by $12 \%$ SDSpolyacrylamide gel electrophoresis at $70 \mathrm{~V}$ for $30 \mathrm{~min}$ and $100 \mathrm{~V}$ for $1 \mathrm{~h}$. Then protein was transferred to polyvinylidene fluoride membranes $(0.45 \mu \mathrm{m}$, Millipore Co. Ltd.) at $350 \mathrm{~mA}$ for $1 \mathrm{~h}$. After blocking with 5\% nonfat milk in Tris-buffered saline with Tween 20 for $1 \mathrm{~h}$ at room temperature and then washing three times with TBST, the membranes were incubated with primary antibodies against BAX (1:1000,
Cell Signaling Technology), Bcl-2 (1:1000, Abcam), caspase-3 (1:1000, Cell Signaling Technology), AKT (1:1000, Cell Signaling Technology), p-AKT-Ser473 (1:2000, Cell Signaling Technology), Nox1 (1:1000, Abcam), Nox4 (1:1000, Abcam), and Nox2 (1:5000, Abcam) overnight at $4^{\circ} \mathrm{C}$. $\beta$-Actin $(1: 1000$, Cell Signaling Technology) was used as the control protein. The next day, the membranes were washed three times with TBST and incubated with an HRP-conjugated secondary antibody ( $1: 1000$, Cell Signaling Technology) for $1 \mathrm{~h}$ at room temperature. Bound antibody was detected with an Amersham Imager 600, and densitometric analysis of the images was performed using the ImageJ image processing program.

2.3. Flow Cytometric Assays. The FITC Annexin V Apoptosis Detection Kit I (BD Pharmingen, 556547) was used to detect apoptosis of $\mathrm{H} 9 \mathrm{c} 2$ cells according to the manufacturer's instructions. H9c2 cells were trypsinized and then centrifuged at $1000 \mathrm{rpm}$ for $5 \mathrm{~min}$ at room temperature. The cells were washed twice in cold $\left(4^{\circ} \mathrm{C}\right) \mathrm{PBS}$, centrifuged again, and then resuspended in $300 \mu \mathrm{L}$ of $1 \times$ binding buffer. The resuspended cells were incubated with $5 \mu \mathrm{L}$ of Annexin $\mathrm{V}$-FITC and $5 \mu \mathrm{L}$ of propidium iodide (PI) staining solution for $15 \mathrm{~min}$ without light at room temperature. After adding $200 \mu \mathrm{L}$ of $1 \times$ binding buffer, the cells were detected by flow cytometry on a FACS Calibur (BD Biosciences) within $1 \mathrm{~h}$. The data were analyzed by FlowJo 7.6 software. The percentage of stained cells to total cells was computed as the ratio of apoptotic cells.

2.4. TUNEL Assay. Apoptosis in H9c2 cells was detected by using a high-sensitive one-step terminal deoxyribonucleotide transferase dUTP nick end labelling (TUNEL) apoptosis assay kit (Beyotime Institute of Biotechnology, Jiangsu, China) according to the manufacturer's instructions. In brief, $\mathrm{H} 9 \mathrm{c} 2$ cells were fixed with $4 \%$ paraformaldehyde for $30 \mathrm{~min}$. After washing with PBS, using $0.3 \%$ Triton X-100, H9c2 cells were permeabilized. Then they were incubated with $50 \mu \mathrm{L}$ TUNEL reaction fluid in a humid environment at $37^{\circ} \mathrm{C}$ for $1 \mathrm{~h}$. And after washing twice with PBS, H9c2 cells were incubated with $4^{\prime}$, 6-diamidino-2-phenylindole (DAPI) to stain nuclei. Finally, H9c2 cells were observed under fluorescence microscope.

2.5. DHE Staining. Total $\mathrm{O}_{2}{ }^{-}$production by $\mathrm{H} 9 \mathrm{c} 2$ cells was measured by using dihydroethidium (DHE) (Sigma, CAS 104821-25-2). DHE is oxidized by intracellular $\mathrm{O}_{2}^{-}$and then it combines with the chromosomal DNA in the nucleus to generate red fluorescence. Treated H9c2 cells were washed twice with PBS. The washed cells were incubated with $20 \mu \mathrm{M}$ DHE diluted in $2 \mathrm{~mL}$ serum-free DMEM without light at $37^{\circ} \mathrm{C}$. $\mathrm{H} 9 \mathrm{c} 2$ cells were washed three times again with $2 \mathrm{~mL}$ PBS after $30 \mathrm{~min}$ incubation and then fluorescence microscopy was used to observe the red fluorescent images. ImageJ software was used to analyze the fluorescence intensity. The ratio of fluorescence intensity to the basal level was quantified and regarded as the cellular $\mathrm{O}_{2}^{-}$level.

2.6. ESR Assays. In order to detect the $\mathrm{O}_{2}{ }^{-}$production which is dependent on Nox, we mixed $10 \mu \mathrm{L}$ of the protein samples 

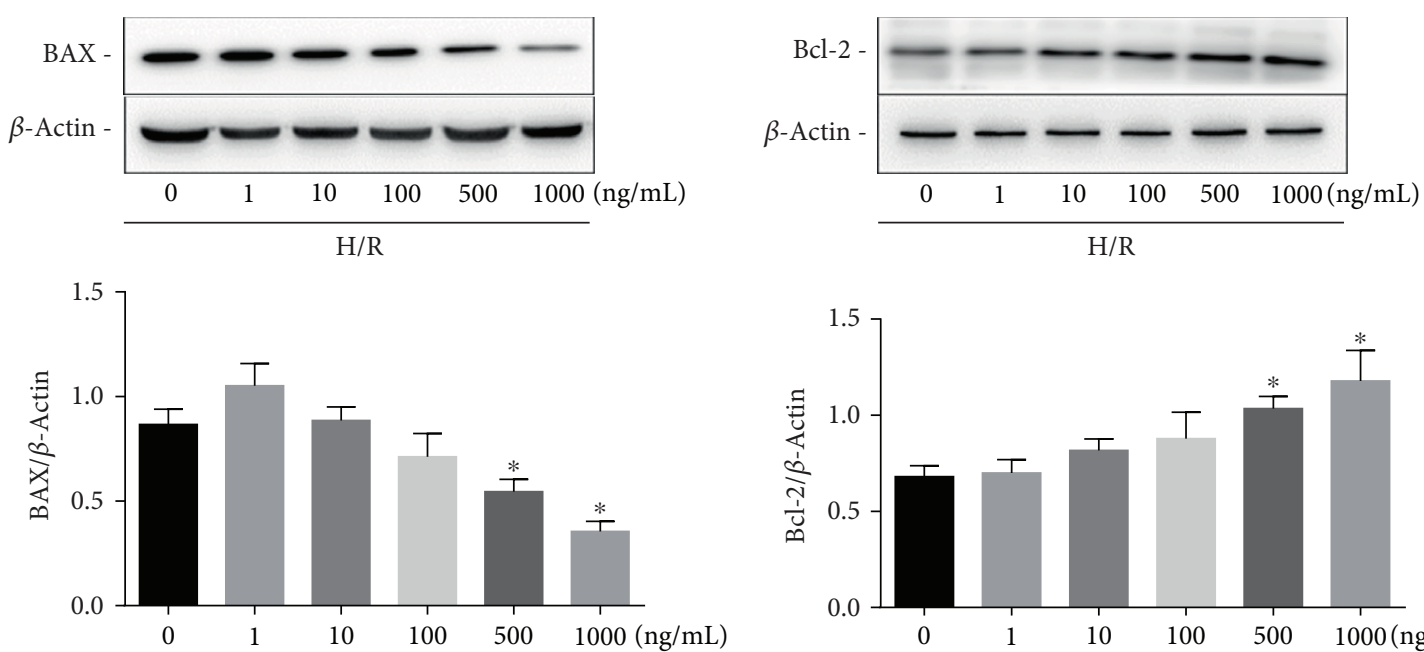

(a)

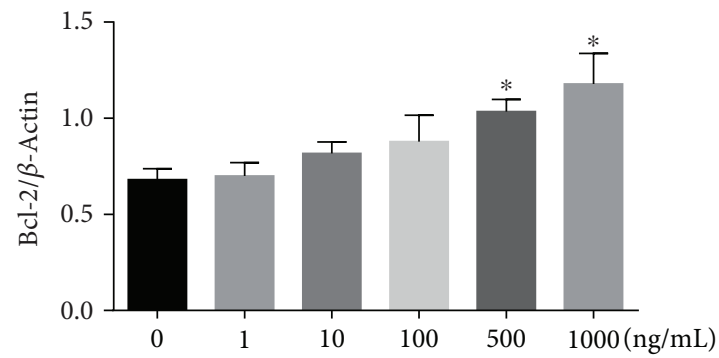

(b)
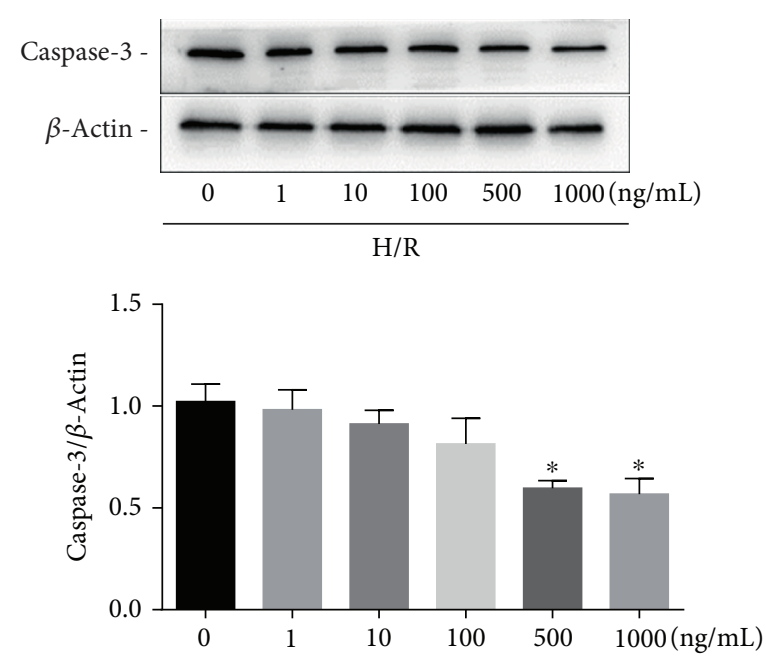

(c)

Figure 1: Expression of apoptosis-associated proteins induced by hypoxia/reoxygenation at different concentrations of CyPA. H9c2 cells were incubated with different concentrations of CyPA $(0,1,10,100,500$, and $1000 \mathrm{ng} / \mathrm{mL})$ for $18 \mathrm{~h}$ of hypoxia and $4 \mathrm{~h}$ of reoxygenation. The protein expression levels of BAX, Bcl-2, and caspase- 3 are revealed in the representative western blot gel files and summarized data $(\mathrm{a}-\mathrm{c}) .{ }^{*} p<0.05$ vs. the control group $(n=4)$.

collected from the $\mathrm{H} 9 \mathrm{c} 2$ cells with $80 \mu \mathrm{L}$ of a solution made of Krebs-HEPES buffer which also contained diethyldithiocarbamate (5 $\mu \mathrm{M}$, Sigma) and deferoxamine ( $25 \mu \mathrm{M}$, Sigma) and followed this by the addition of the cell-permeable spin probe 1-hydroxy-3-methoxycarbonyl2,2,5,5-tetramethylpyrrolidine ( $\mathrm{CMH}$; ENZO, Alexis Corporation) to a concentration of $1 \mathrm{mM}$ and the substrate NADPH (Beyotime Biotechnology) to a concentration of $20 \mu \mathrm{M}$, with or without manganese-dependent superoxide dismutase (SOD, $8000 \mathrm{U} / \mathrm{mL}$; Beyotime Biotechnology). An electron spin resonance (ESR) spectrometer (Bruker, Germany) was used to analyze $\mathrm{O}_{2}^{-}$production in the protein samples. In the homogenates, the SOD-inhibitable fraction of the signal showed the total $\mathrm{O}_{2}{ }^{-}$production, and the results were indicated as fold changes compared with controls.

2.7. Confocal Microscopy Assay. A nuclear location of NOX2 in $\mathrm{H} 9 \mathrm{c} 2$ cells was observed by confocal microscopy. In brief,
H9c2 cells were fixed with $4 \%$ paraformaldehyde for $10 \mathrm{~min}$. And after washing twice with PBS, using $0.5 \%$ Triton X-100, $\mathrm{H} 9 \mathrm{c} 2$ cells were permeabilized. After washing twice again, using 1\% Bull Serum Albumin (BSA) to block cells for $30 \mathrm{~min}$ at room temperature and then washing three times with PBS, the cells were incubated with primary antibodies against Nox2 (1:5000, Abcam) overnight at $4^{\circ} \mathrm{C}$. The next day, the cells were washed three times with PBS and incubated with Goat Anti-Rabbit IgG (H\&L) Alexa Fluor 594 secondary antibody $(1: 200$, Abcam) for $2 \mathrm{~h}$ at room temperature. After washing twice with PBS, H9c2 cells were incubated with $4^{\prime}$, 6-diamidino-2-phenylindole (DAPI) to stain nuclei for $30 \mathrm{~min}$ without light. Finally, H9c2 cells were observed under confocal microscopy.

2.8. Statistical Analysis. Data are presented as the mean \pm SE. The significance of the differences between two groups was examined using Student's $t$-test followed by Duncan's 


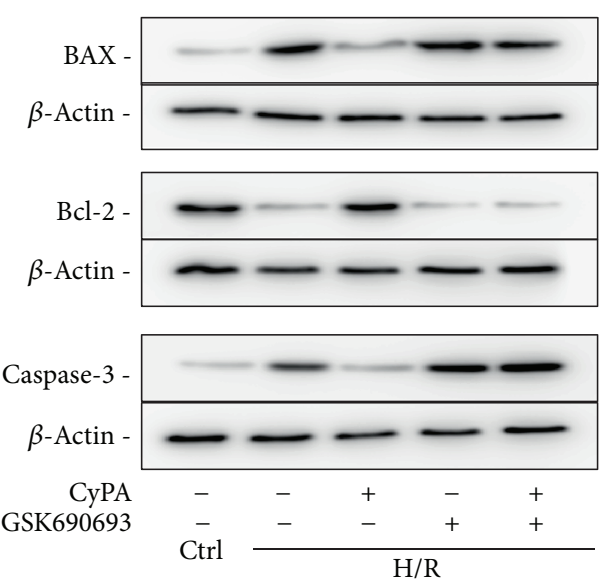

(a)

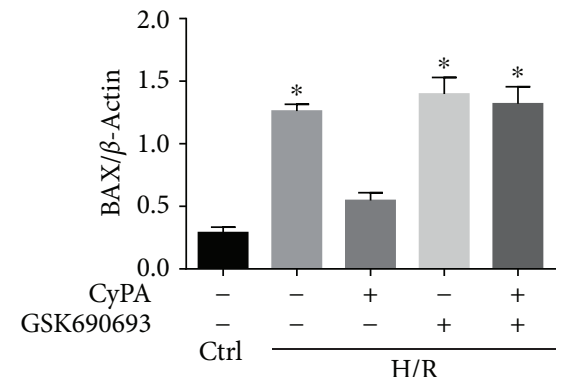

(b)

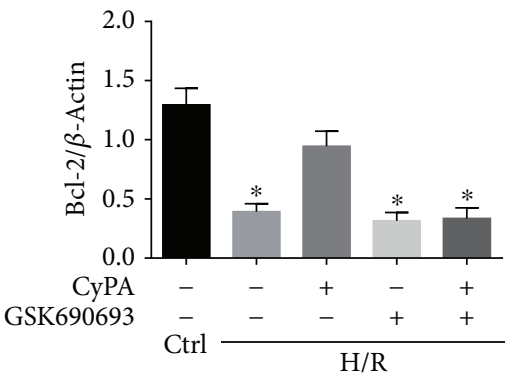

(c)

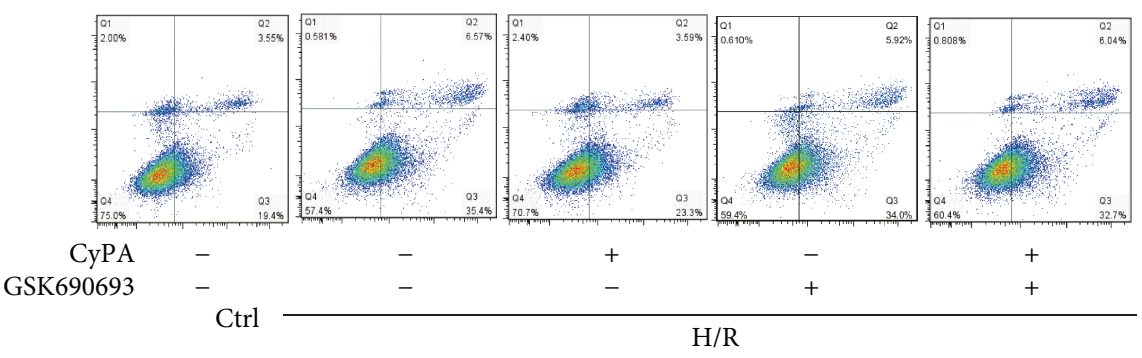

(d)

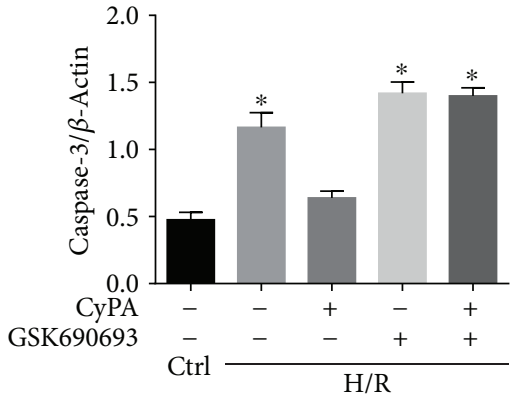

(e)

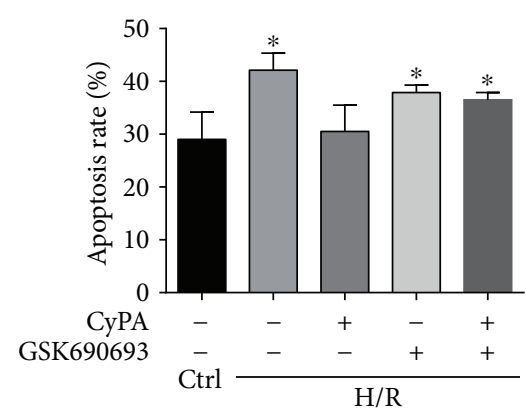

(f)

FIGURE 2: CyPA inhibits apoptosis of $\mathrm{H} 9 \mathrm{c} 2$ cells under hypoxia/reoxygenation conditions. H9c2 cells were divided into five groups, control (cultured for $22 \mathrm{~h}$ under normoxic conditions), H/R (cultured for $18 \mathrm{~h}$ of hypoxia followed by $4 \mathrm{~h}$ of reoxygenation), H/R+CyPA $(1000 \mathrm{ng} / \mathrm{mL}), \mathrm{H} / \mathrm{R}+\mathrm{GSK} 690693(10 \mu \mathrm{M})$, and H/R+CyPA $(1000 \mathrm{ng} / \mathrm{mL})+\mathrm{GSK} 690693(10 \mu \mathrm{M})$. The protein expression levels of BAX, $\mathrm{Bcl}-2$, and caspase- 3 are revealed in the representative western blot gel files and summarized data (a-c, e). The apoptotic populations of H9c2 cells sorted by flow cytometry after double staining with FITC-Annexin V and propidium iodide (PI) are revealed in representative plots (d) and summarized data (f). ${ }^{*} p<0.05$ vs. the H/R+CyPA group $(n=4)$.

multiple-range test. Values of $p<0.05$ were considered statistically significant.

\section{Results and Discussion}

3.1. CyPA Inhibits Apoptosis of H9c2 Cells under Hypoxia/Reoxygenation Conditions. In a variety of cell types, $\mathrm{BAX}$ and $\mathrm{Bcl}-2$ can control proapoptotic and antiapoptotic intracellular signals which are very important in programmed cell death. In addition, the activation of caspase- 3 also mediates apoptosis. Our preliminary experiments showed that $\mathrm{H} 9 \mathrm{c} 2$ cells underwent significant apoptosis after $18 \mathrm{~h}$ of hypoxia and $4 \mathrm{~h}$ of reoxygenation. In these cells, we detected a large amount of ROS by DHE staining (not shown). We determined the concentration of CyPA needed for intervention and the effect of CyPA on $\mathrm{H} 9 \mathrm{c} 2$ cells under H/R. On western blot analysis, we found that the most remarkable changes of BAX, Bcl-2, and caspase- 3 occurred in response to $1000 \mathrm{ng} / \mathrm{mL}$ of CyPA (Figures $1(\mathrm{a})-1(\mathrm{c})$ ). CyPA remarkably reduced the protein levels of BAX and caspase-3 (Figures 2(a), 2(b), and 2(e)). In contrast, expression of $\mathrm{Bcl}-2$ was significantly increased in response to CyPA (Figures 2(a) and 2(c)). However, treatment with GSK690693 (a pan-Akt inhibitor targeting Akt1/2/3) prevented the effects of $\mathrm{CyPA}$, and the expression levels of all apoptotic proteins in the H/R+CyPA+GSK690693 group 


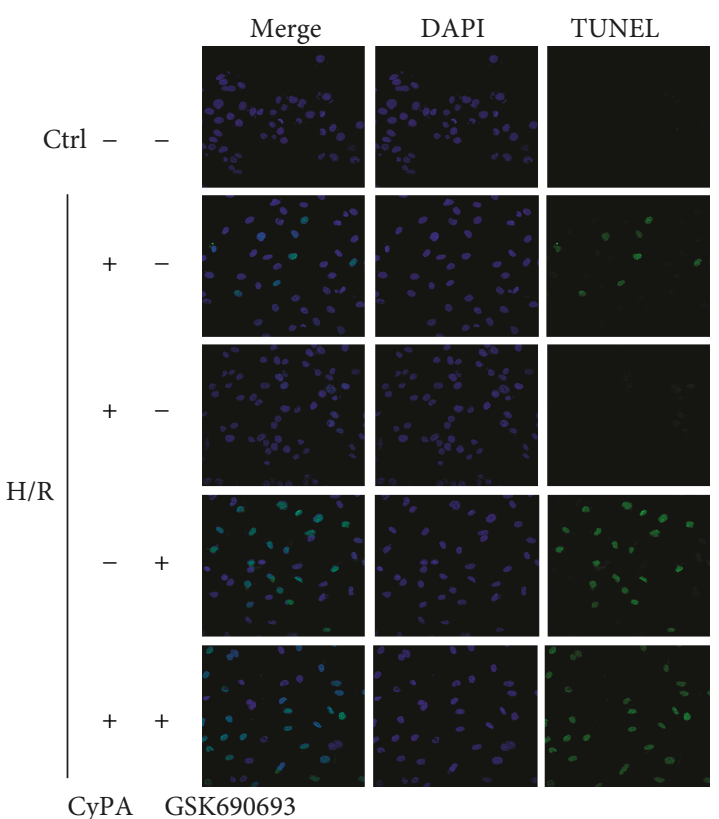

(a)

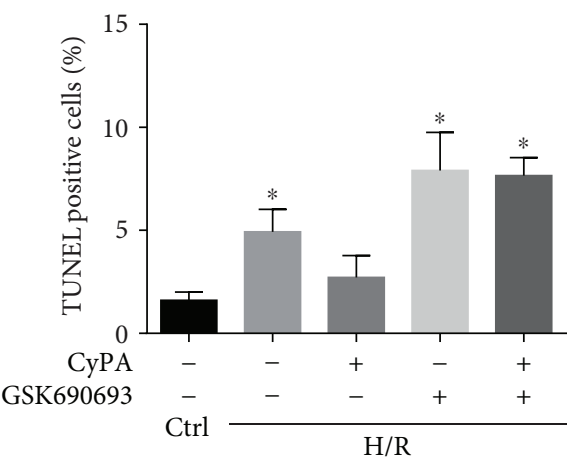

(b)

FIGURE 3: Representative fluorescent images of TUNEL assay and summarized data showing the TUNEL cells. Photographs were at $\times 400$ magnification. ${ }^{*} p<0.05$ vs. the $\mathrm{H} / \mathrm{R}+\mathrm{CyPA}$ group $(n=3)$.

were almost the same as those in the H/R+GSK690693 group (Figures 2(a)-2(c) and 2(e)). Annexin V-FITC/PI double staining was further used for flow cytometric assays to investigate the roles of CyPA in opposing apoptosis induced by hypoxia/reoxygenation. The results indicated that the percentage of $\mathrm{H} 9 \mathrm{c} 2$ cells which bound Annexin V-FITC increased from $22.95 \%$ in the control group to $41.97 \%$ in the $\mathrm{H} / \mathrm{R}$ group, while $\mathrm{CyPA}$ intervention significantly inhibited apoptosis, resulting in only $26.89 \%$ apoptotic cells. However, the percentage of cells in apoptosis increased to $38.74 \%$ in the H/R+CyPA+GSK690693 group (Figures 2(d) and 2(f)). And the percentage of cells in apoptosis is $39.92 \%$ in the H/R+GSK690693 group (Figures 2(d) and 2(f)).

We also further verified this result with the TUNEL kit. Normal cells hardly showed green fluorescence; TUNEL cells increased significantly in the H/R group and this situation improved after CyPA stimulation. But TUNEL cells increased again in the $\mathrm{H} / \mathrm{R}+\mathrm{GSK} 690693$ group and the H/R+CyPA+GSK690693 group (Figure 3). These data consistently demonstrated the antiapoptotic role of CyPA in H9c2 cells under $H / R$ conditions and showed that this may occur by activating the AKT pathway.

3.2. CyPA Decreased $\mathrm{O}_{2}^{-}$Production under Hypoxial Reoxygenation Conditions. To further explore the antioxidant effect of CyPA, we tested if CyPA treatment altered the production of $\mathrm{O}_{2}^{-}$, a critical prooxidative stress factor. We used fluorescent spectrometry of a fluorescent probe, dihydroethidium (DHE), to detect intracellular $\mathrm{O}_{2}{ }^{-}$production. $\mathrm{H} 9 \mathrm{c} 2$ cells showed a strong red fluorescence produced from DHE oxidization by $\mathrm{O}_{2}{ }^{-}$under $\mathrm{H} / \mathrm{R}$ conditions. CyPA intervention obviously blocked the increase of fluorescence intensity which occurred in response to H/R. However, the
H/R+GSK690693 group and the H/R+CyPA+GSK690693 group showed a strong red fluorescence (Figures 4(a) and 4(b)). By using ESR spectrometry, we further defined the role of CyPA in hypoxia/reoxygenation-induced $\mathrm{O}_{2}{ }^{-}$production in $\mathrm{H} 9 \mathrm{c} 2$ cells. Changes in ESR spectra were superoxide dismutase- (SOD-) inhibitable, as shown by the representative spectra in Figure 4(c). The summarized data in Figure 4(d) show that hypoxia/reoxygenation significantly increased $\mathrm{O}_{2}{ }^{-}$production dependent on NADPH oxidase in the $\mathrm{H} 9 \mathrm{c} 2$ cells, and this was significantly weakened by CyPA intervention, but $\mathrm{O}_{2}{ }^{-}$production was significantly increased again in the H/R+GSK690693 group and the $\mathrm{H} / \mathrm{R}+\mathrm{CyPA}+\mathrm{GSK} 690693$ group. In short, these assays showed that $\mathrm{CyPA}$ indeed played an antioxidant role by inhibiting NADPH oxidase-dependent $\mathrm{O}_{2}^{-}$production.

3.3. AKT/Nox2 Pathway Mediates the Role of CyPA in Opposing Hypoxia/Reoxygenation-Induced Apoptosis. The downregulation of the production of $\mathrm{O}_{2}{ }^{-}$strongly suggests involvement of the Nox2 pathway. We therefore tested the expression of Nox2 in CyPA-treated H9c2 cells by western blot analysis. As shown in Figures 5(a) and 5(b), expression of the Nox 2 protein was remarkably reduced compared with the H/R group after CyPA intervention. The level of Nox2 protein is increased compared with the control group under $\mathrm{H} / \mathrm{R}$ conditions (Figures 5(a) and 5(b)); to investigate the upstream pathway leading to the upregulation of Nox2 protein, we determined the activities of AKT (protein kinase B). The protein levels of $\mathrm{p}$-AKT were increased significantly in response to CyPA (Figures 5(c), 5(e), and 5(f)). Although Nox2 protein has the most expression in cardiomyocytes, we have also detected other NADPH oxidases, Nox1 and Nox4, which have been shown in cardiomyocytes. We found that 

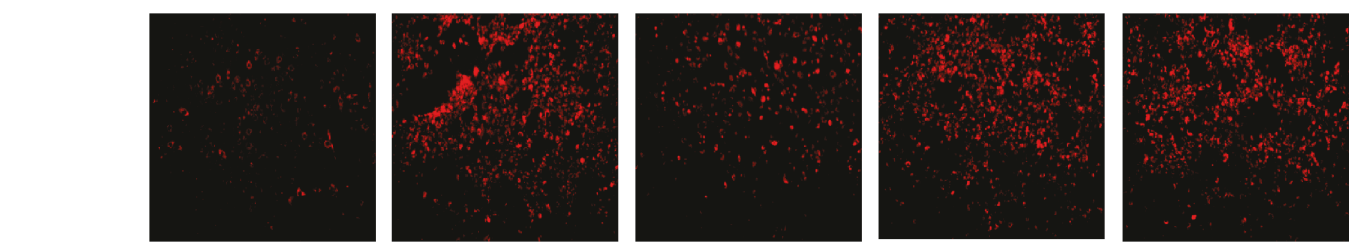

CyPA

GSK690693

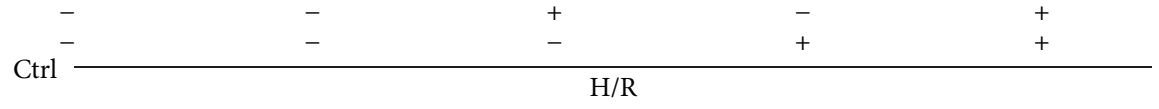

(a)

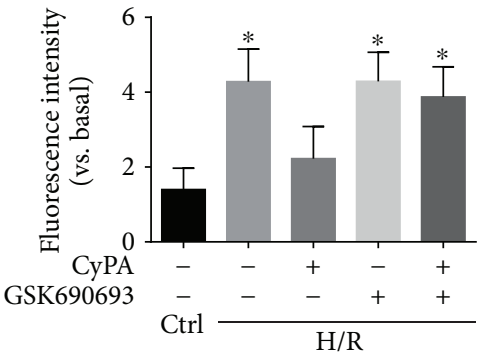

(b)

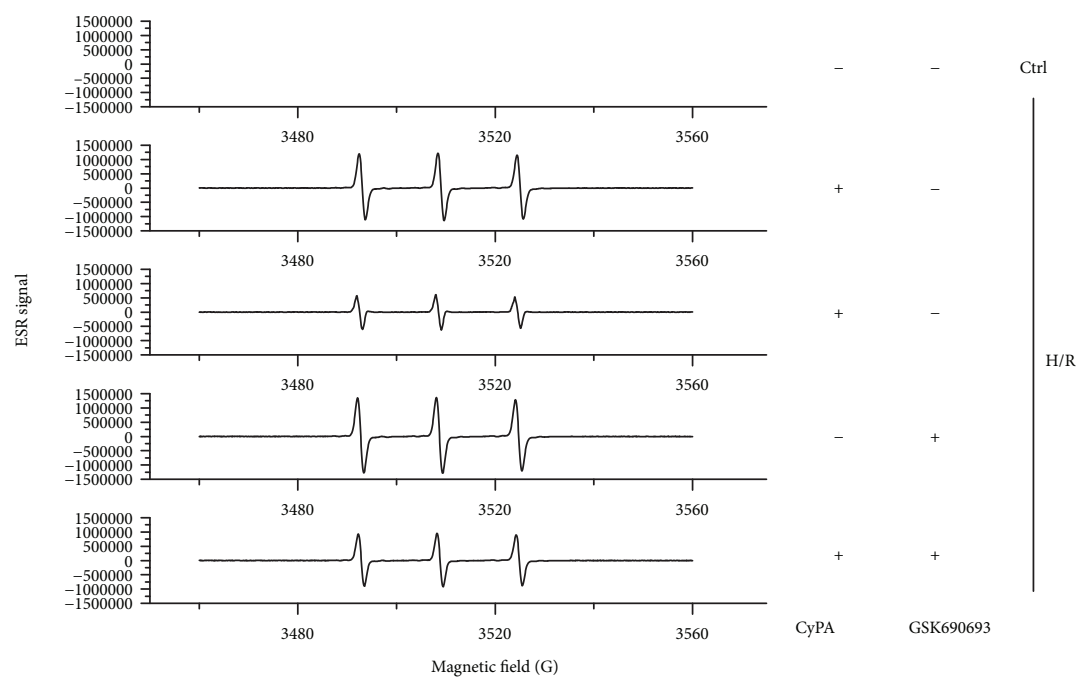

(c)

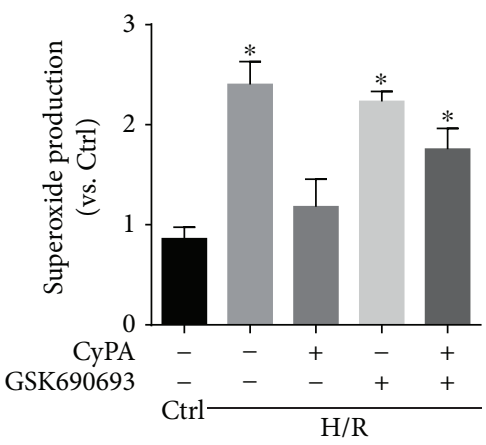

(d)

FIgure 4: CyPA decreased $\mathrm{O}_{2}^{-}$production under hypoxia/reoxygenation conditions. The roles of CyPA $(1000 \mathrm{ng} / \mathrm{L})$ on $\mathrm{O}_{2}^{-}$production in $\mathrm{H} 9 \mathrm{c} 2$ cells incubated under $\mathrm{H} / \mathrm{R}$ conditions and the changes in the roles of CyPA $(1000 \mathrm{ng} / \mathrm{mL})$ on $\mathrm{O}_{2}^{-}$production after GSK690693 $(10 \mu \mathrm{M})$ intervention are revealed in representative fluorescent images for DHE staining (a) and summarized data (b). Photographs were taken at $\times 100$ magnification. The $\mathrm{O}_{2}^{-}$production dependent on NADPH oxidase in the H9c2 cells is revealed in representative ESR CM nitroxide spectra resulting from $\mathrm{CMH}$ reacted with $\mathrm{O}_{2}{ }^{-}$(c) and summarized data (d). ${ }^{*} p<0.05$ vs. the $\mathrm{H} / \mathrm{R}+\mathrm{CyPA}$ group $(n=4)$. 


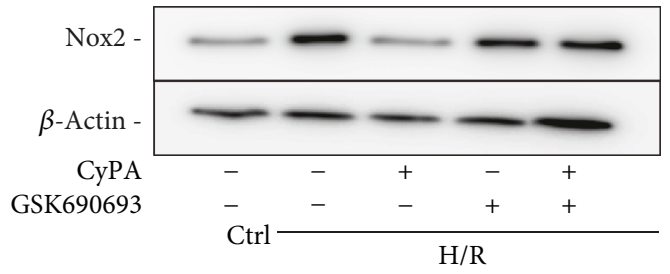

(a)

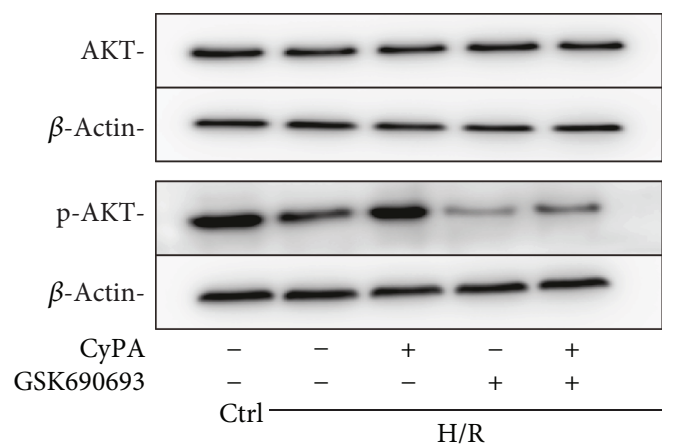

(c)

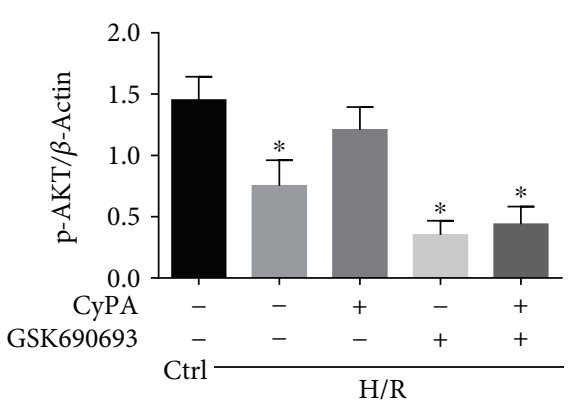

(e)

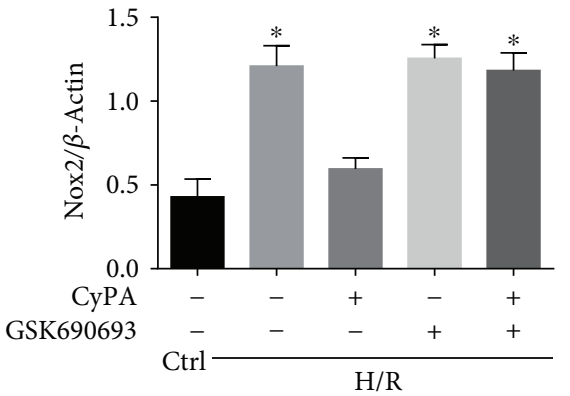

(b)

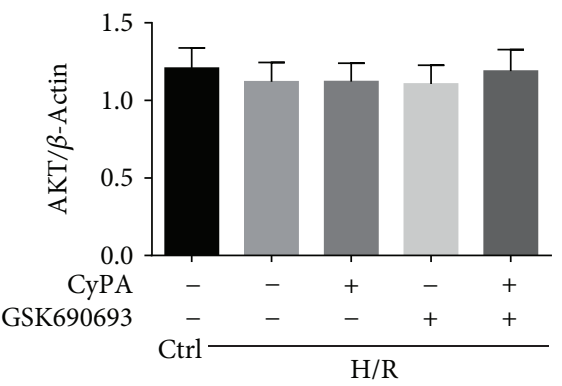

(d)

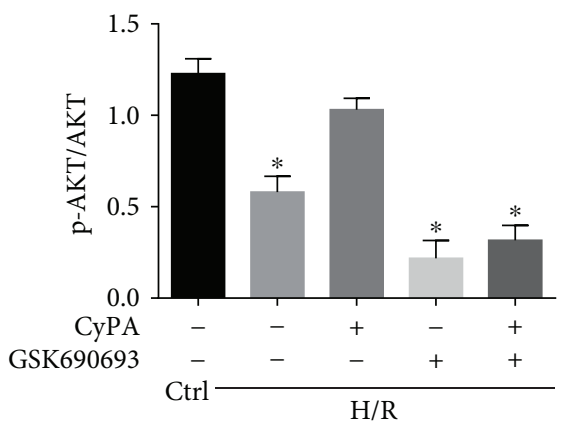

(f)

Figure 5: The AKT/Nox2 pathway mediates the role of CyPA in opposing hypoxia/reoxygenation-induced apoptosis, whereas inhibiting the AKT/Nox2 pathway partially abrogates CyPA-mediated protection under hypoxia/reoxygenation conditions. The expression of AKT, $\mathrm{p}-\mathrm{AKT}$, and Nox 2 protein is revealed in representative western blot gel files and summarized data $(\mathrm{a}-\mathrm{f}) .{ }^{*} p<0.05 \mathrm{vs}$. the H/R+CyPA group $(n=4)$.

Nox1 protein and Nox4 protein were rarely expressed in H9c2 cells and they were not significantly increased under H/R conditions (Figure 6). These results are in agreement with the hypothesis that the AKT/Nox2 pathway mediates the role of CyPA in opposing hypoxia/reoxygenationinduced apoptosis in $\mathrm{H} 9 \mathrm{c} 2$ cells.

\subsection{Inhibiting the AKT/Nox2 Pathway Partially Abrogates} CyPA-Mediated Protection under Hypoxia/Reoxygenation Conditions. We inhibited the AKT/Nox2 signaling pathway by using GSK690693, a pan-Akt inhibitor targeting Akt $1 / 2 / 3$, to determine whether there was a direct link between the effects of CyPA on AKT/Nox2 pathway activation and apoptosis. We found that the protein levels of p-AKT were significantly reduced, and the expression of Nox2 is remarkably increased, compared to the H/R+CyPA group after GSK690693 treatment (Figures 5(a)-5(f)). These results suggested that $\mathrm{CyPA}$ in $\mathrm{H} 9 \mathrm{c} 2$ cells loses its antioxidant capacity under $\mathrm{H} / \mathrm{R}$ conditions when the AKT/Nox2 pathway is inhibited.

3.5. CyPA Reduced the Expression of Nox2 Membrane-Bound Subunits to Protect Cardiomyocytes against H/R-Induced Apoptosis via the AKT/Nox2 Pathway. To further demonstrate that CyPA inhibits the expression of Nox2 via the AKT/Nox2 signaling pathway in $H / R$ conditions, we used GSK2795039 (a NADPH oxidase 2 inhibitor) to inhibit the activity of Nox2. We found that the protein levels of BAX, caspase-3, and Nox2 were remarkably reduced in the $\mathrm{H} / \mathrm{R}+\mathrm{CyPA}$ group and the $\mathrm{H} / \mathrm{R}+\mathrm{GSK} 2795039$ group (Figures $7(\mathrm{a}), 7(\mathrm{~b}), 7(\mathrm{~d})$, and $7(\mathrm{e})$ ), and the expression of Bcl-2 was significantly increased in both the two groups (Figure $7(\mathrm{c})$ ). In brief, CyPA inhibits the activity of Nox2 by activating the AKT signaling pathway. And we used 

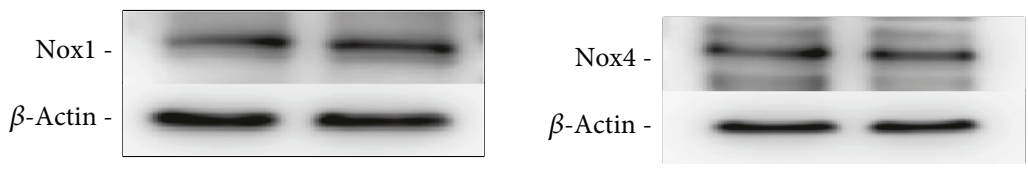

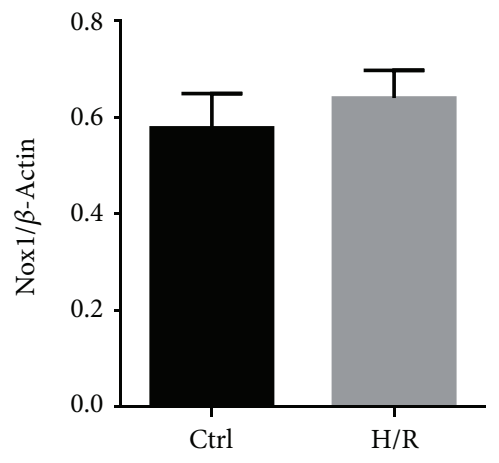

(a)

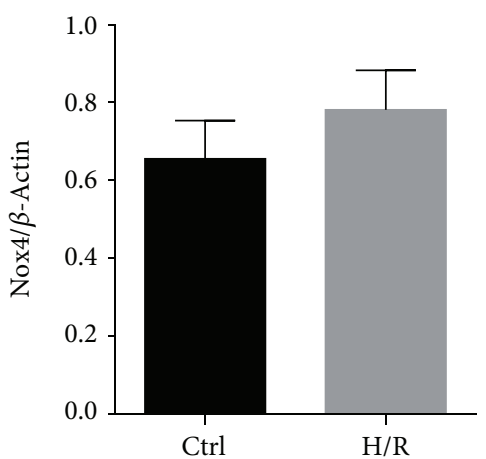

(b)

Figure 6: The protein expression levels of Nox1 and Nox4 are revealed in the representative western blot gel files and summarized data (a, b). ${ }^{*} p<0.05$ vs. the Ctrl group $(n=3)$.
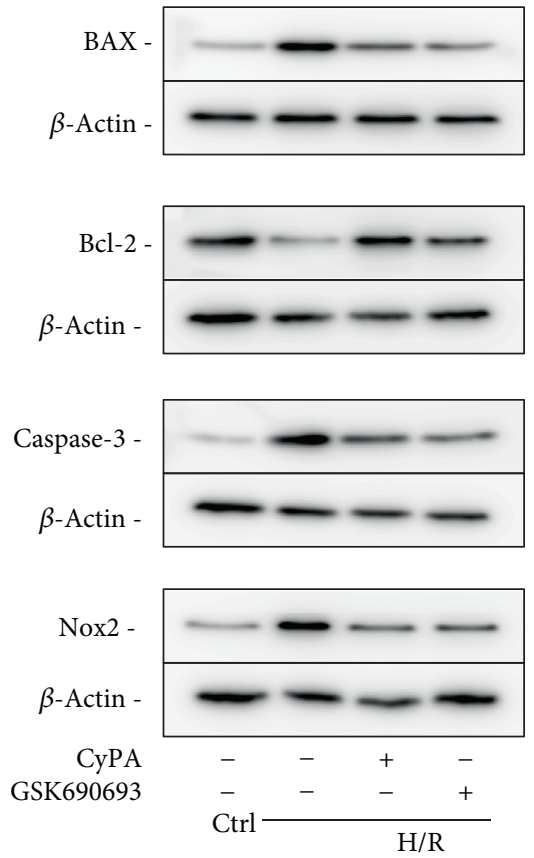

(a)

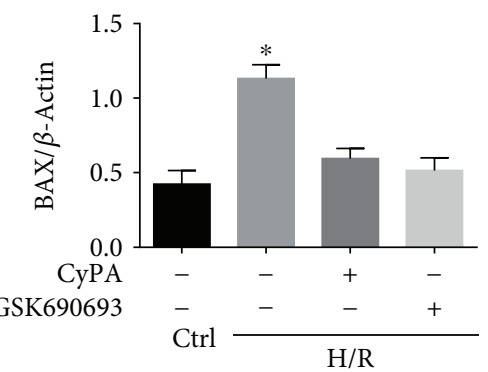

(b)

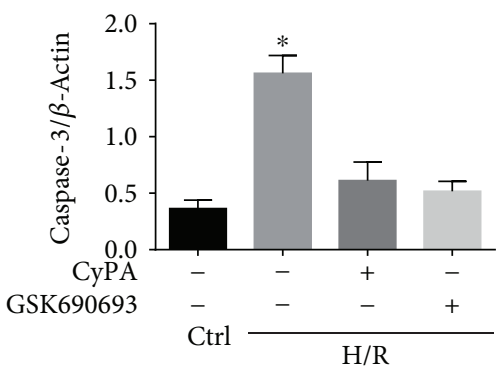

(d)

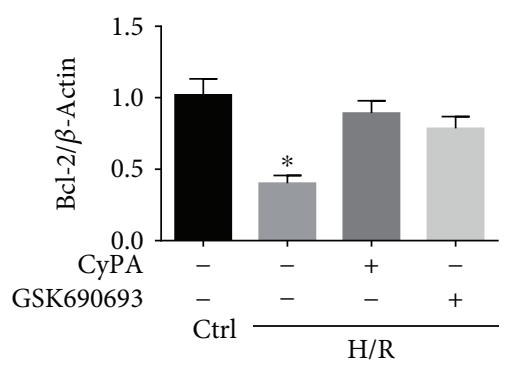

(c)

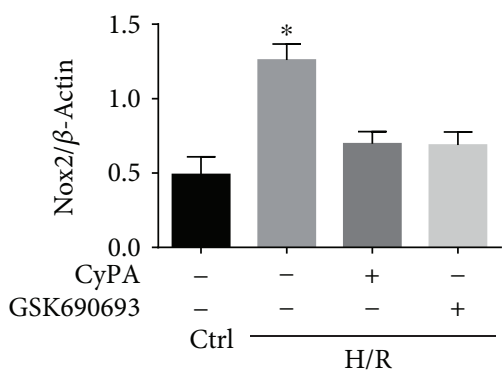

(e)

FiguRE 7: H9c2 cells were divided into four groups, control (cultured for $22 \mathrm{~h}$ under normoxic conditions), H/R (cultured for $18 \mathrm{~h}$ of hypoxia followed by $4 \mathrm{~h}$ of reoxygenation), H/R+CyPA (1000 ng/mL), and H/R+GSK2795039 (10 $\mu \mathrm{M})$. The protein expression levels of BAX, Bcl-2, caspase-3, and Nox 2 are revealed in the representative western blot gel files and summarized data $(\mathrm{a}-\mathrm{e}) .{ }^{*} p<0.05 \mathrm{vs}$. the H/R+CyPA group $(n=3)$.

confocal microscopy to observe the changes of Nox2 distribution in $\mathrm{H} 9 \mathrm{c} 2$ cells. As shown in Figure 8, in normal state, Nox2 is distributed in the cytoplasm of H9c2 cells. After H/R stimulation, the expression of Nox 2 on the plasma membrane increases, suggesting the role of Nox 2 on apoptosis, which is modified by CyPA or GSK2795039 treatment. Regarding the present study, Nox2 appears to lead to cell apoptosis, by cytosolic subunit translocation-induced activation. These results are in agreement with the finding that $\mathrm{CyPA}$ reduced the expression of Nox 2 membranebound subunits to protect cardiomyocytes against H/Rinduced apoptosis via the AKT/Nox2 pathway.

3.6. Schematic Figure of Mechanism. In H/R condition, activated Nox 2 can translocate to the biological membrane to increase the ROS production and then ROS upregulates 


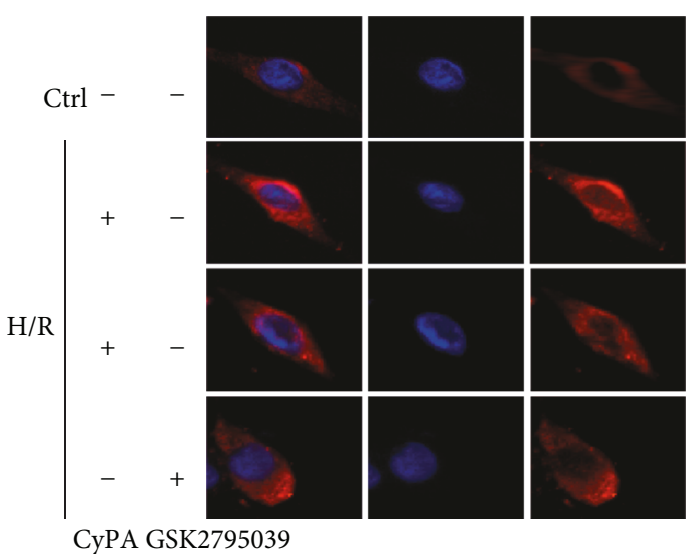

(a)

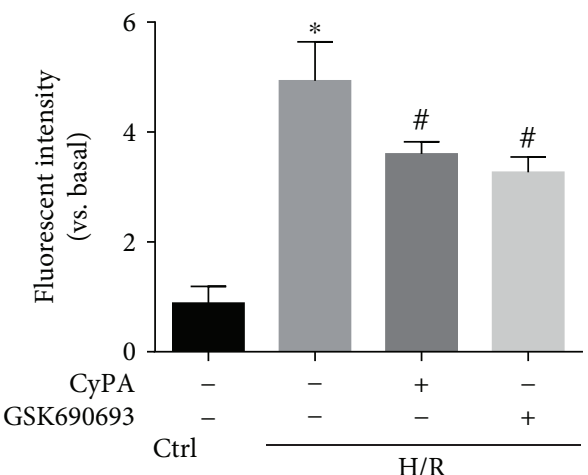

(b)

FIGURE 8: Typical representative fluorescent images showed changes of Nox2 distribution in H9c2 cells. The red-stained Nox2 moves from the cytoplasm to the plasma membrane, together with the increase of red fluorescence intensity by confocal microscopy (a) and summarized data (b). The nucleus is dyed by DAPI staining. Magnification $63 \mathrm{x}$, scale bars: $10 \mu \mathrm{m} .{ }^{*} p<0.05$ vs. the Ctrl group $(n=3)$. ${ }^{\#} p<0.05$ vs. the H/R group $(n=3)$.

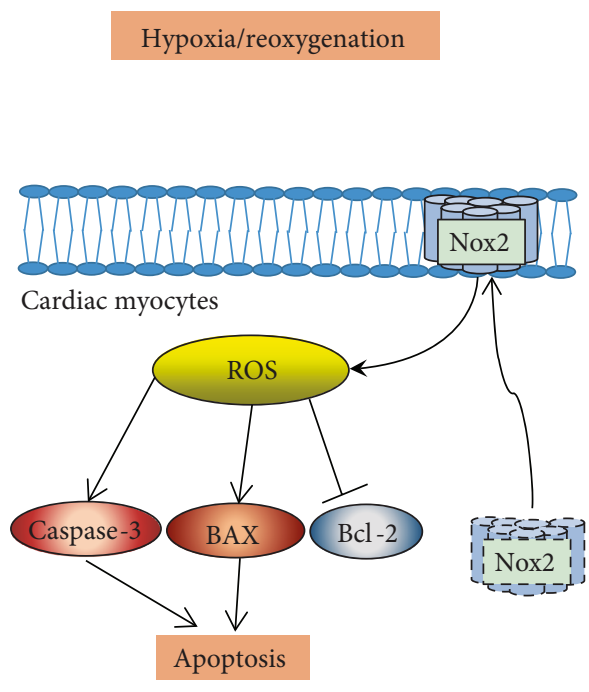

(a)

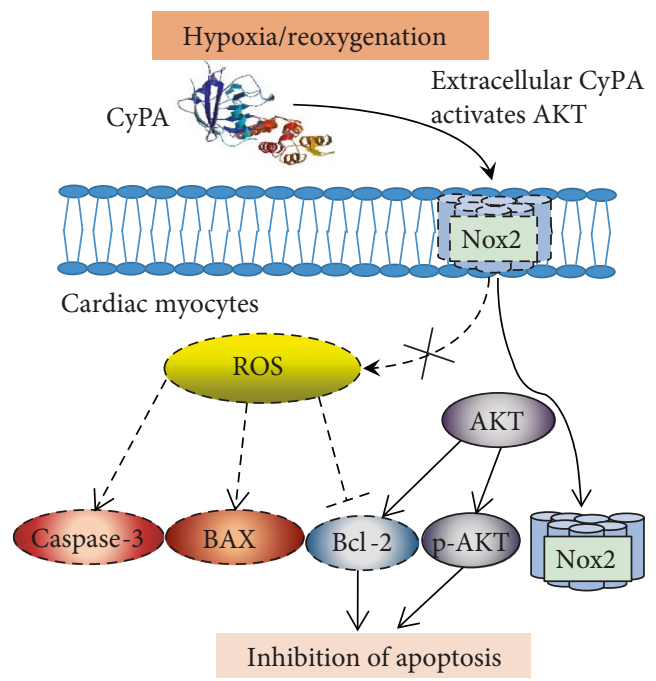

(b)

FIGURE 9: Schematic figure of mechanism.

the expression of caspase- 3 and BAX and downregulates the expression of Bcl-2 to mediate apoptosis of cardiomyocytes (Figure 9(a)) by activating the AKT pathway. CyPA can reduce the ROS production while upregulating the expression of $\mathrm{Bcl}-2$, $\mathrm{p}$-AKT protein to inhibit cardiomyocyte apoptosis through this process (Figure 9(b)).

\section{Conclusions}

Until now, the role of CyPA in VSMCs and endothelial cells (ECs) has been studied in depth, but the role of CyPA in cardiomyocytes under $\mathrm{H} / \mathrm{R}$ conditions has not been extensively studied. In VSMCs, CyPA promotes ROS production, and ROS further stimulates VSMC to secrete more CyPA, leading to the continuation and expansion of oxidative stress $[11-13,16,17]$. In ECs, studies have shown that CyPA can simultaneously activate the antiapoptotic and proapoptotic signaling pathways of ECs when stimulated by inflammatory factors such as ROS [23]. In addition, studies have shown that these dual effects of CyPA on ECs may be dependent on CyPA concentration [24]. In this study, we found that CyPA significantly inhibited the apoptosis of H9c2 cardiomyocytes under $\mathrm{H} / \mathrm{R}$ conditions. However, CyPA in $\mathrm{H} 9 \mathrm{c} 2$ cells lost its antioxidant capacity after using the p-AKT inhibitor. Considering that ROS mediates cellular injury in the cardiovascular system under H/R conditions [25], we believe that $\mathrm{CyPA}$ protects $\mathrm{H} 9 \mathrm{c} 2$ cells against oxidative stress at least in part by inhibiting $\mathrm{O}_{2}{ }^{-}$production. In order to confirm this, we examined the levels of $\mathrm{O}_{2}{ }^{-}$by DHE staining. Our experimental data showed that CyPA significantly reduced $\mathrm{O}_{2}^{-}$production in $\mathrm{H} 9 \mathrm{c} 2$ cardiomyocytes under $\mathrm{H} / \mathrm{R}$ conditions. We also found that the production of $\mathrm{O}_{2}{ }^{-}$was not 
reduced by $\mathrm{CyPA}$ stimulation in the $\mathrm{p}$-AKT inhibitor GSK690693-treated group. We further confirmed this by ESR assays. One of the main sources of $\mathrm{O}_{2}{ }^{-}$produced in the cardiovascular system is the NADPH oxidase enzymes [26]. The activation of these enzymes has been implicated in apoptosis. Studies have shown that Nox2 is expressed in the nucleus of cardiomyocytes during apoptosis and may be involved in proapoptotic signaling [27]. Therefore, we further tested the expression of Nox 2 protein and also investigated the upstream AKT pathway and its activities. We found that $\mathrm{CyPA}$ in $\mathrm{H} 9 \mathrm{c} 2$ cells mediates the activation of AKT to downregulate the expression of Nox 2 protein and reduces the expression of Nox 2 membrane-bound subunits, ultimately reducing the production of $\mathrm{O}_{2}{ }^{-}$under $\mathrm{H} / \mathrm{R}$ conditions. Through this process, CyPA can exhibit its antioxidant function. This is different from what we know about the role of CyPA in VSMCs and ECs. To rule out the effect of DMSO on cells treated with GSK690693, we examined the expression of BAX, Bcl-2, and caspase-3 in H9c2 cells treated with DMSO alone, and the results were not significantly different compared with the control group (data not shown). These results confirm our hypothesis that CyPA protects $\mathrm{H} 9 \mathrm{c} 2$ cardiomyoblasts against $\mathrm{H} / \mathrm{R}$-induced apoptosis via the AKT/Nox2 pathway.

In previous studies on cardiovascular disease, $\mathrm{CyPA}$ was considered to be an inflammatory mediator, inducing apoptosis to various inflammatory cells [12, 28-30]. In addition, studies have shown that CyPA can promote cardiac hypertrophy in a mouse model [31]. However, other studies have shown that CyPA has an antioxidant effect [18-21, 32], and our experimental results demonstrate, for the first time, that CyPA has antioxidant effects on cardiomyocytes under $\mathrm{H} / \mathrm{R}$ conditions. This introduces a new direction for the treatment of acute myocardial infarction and ischemia-reperfusion injury. Related clinical studies have shown that the level of CyPA in the plasma of patients with acute myocardial infarction is significantly increased [33]. On the basis of this study, we have reasons to believe that the increase of CyPA content in the plasma of patients with acute myocardial infarction may possibly protect cardiomyocytes against hypoxia/reoxygenation injury by activating the AKT/Nox2 pathway. However, due to the complex mechanisms in the different cell types, this extracellular CyPA also causes other cell injury by activating different pathways such as ERK1/2, JNK, and p38 [30]. The molecular mechanism of $\mathrm{CyPA}$ as an antioxidant should be explored in future studies. The ultimate goal is to use it to resist oxidative stress without causing other cardiovascular injury.

In conclusion, our data indicate that $\mathrm{CyPA}$ protects $\mathrm{H} 9 \mathrm{c} 2$ cardiomyoblasts against $\mathrm{H} / \mathrm{R}$-induced apoptosis via the AKT/Nox2 pathway. The protective mechanisms of CyPA under oxidative stress give us hope that they may be a potential target for ischemia-reperfusion injury therapy.

\section{Data Availability}

The data used to support the findings of this study are available from the corresponding author upon request.

\section{Conflicts of Interest}

The authors declare that they do not have anything to disclose regarding conflict of interest with respect to this manuscript.

\section{Authors' Contributions}

The first author of this manuscript, Fuyu Cheng, and Wei Yuan designed the experiments and drafted the article. Fuyu Cheng performed and analyzed the western blotting and flow cytometric, dihydroethidium staining, and electron spin resonance assays. Fuyu Cheng and Wei Yuan performed the statistical analysis. Fuyu Cheng, Wei Yuan, Mengfei Cao, Rui Chen, Xiuli Wu, and Jinchuan Yan critically revised the article. The corresponding author, Wei Yuan, suggested the idea. Fuyu Cheng and Wei Yuan contributed equally to this article.

\section{Acknowledgments}

This work was supported by grants from the Jiangsu Provincial Medical Youth Talent (QNRC2016843, WSN-45) and the Jurong Science and Technology Plan (SF2018079430).

\section{References}

[1] R. Handschumacher, M. Harding, J. Rice, R. Drugge, and D. Speicher, "Cyclophilin: a specific cytosolic binding protein for cyclosporin A," Science, vol. 226, no. 4674, pp. 544-547, 1984.

[2] M. W. Harding, R. E. Handschumacher, and D. W. Speicher, "Isolation and amino acid sequence of cyclophilin," The Journal of Biological Chemistry, vol. 261, no. 18, pp. 85478555, 1986.

[3] A. Galat, "Peptidylproline cis-trans-isomerases: immunophilins," European Journal of Biochemistry, vol. 216, no. 3, pp. 689-707, 1993.

[4] M. Theuerkorn, G. Fischer, and C. Schiene-Fischer, "Prolyl cis/trans isomerase signalling pathways in cancer," Current Opinion in Pharmacology, vol. 11, no. 4, pp. 281-287, 2011.

[5] H. Hoffmann and C. Schiene-Fischer, "Functional aspects of extracellular cyclophilins," Biological Chemistry, vol. 395, no. 7-8, pp. 721-735, 2014.

[6] L. Andreeva, R. Heads, and C. J. Green, "Cyclophilins and their possible role in the stress response," International Journal of Experimental Pathology, vol. 80, no. 6, pp. 305-315, 2001.

[7] P. Caroni, A. Rothenfluh, E. McGlynn, and C. Schneider, "S-cyclophilin. New member of the cyclophilin family associated with the secretory pathway," The Journal of Biological Chemistry, vol. 266, no. 17, pp. 10739-10742, 1991.

[8] A. P. Halestrap, C. P. Connern, E. J. Griffiths, and P. M. Kerr, "Cyclosporin A binding to mitochondrial cyclophilin inhibits the permeability transition pore and protects hearts from ischaemia/reperfusion injury," Molecular and Cellular Biochemistry, vol. 174, no. 1/2, pp. 167-172, 1997.

[9] C. P. Connern and A. P. Halestrap, "Recruitment of mitochondrial cyclophilin to the mitochondrial inner membrane under conditions of oxidative stress that enhance the opening of a calcium-sensitive non-specific channel," Biochemical Journal, vol. 302, no. 2, pp. 321-324, 1994. 
[10] J. P. Bourquin, I. Stagljar, P. Meier et al., "A serine/argininerich nuclear matrix cyclophilin interacts with the C-terminal domain of RNA polymerase II," Nucleic Acids Research, vol. 25, no. 11, pp. 2055-2061, 1997.

[11] K. Satoh, H. Shimokawa, and B. C. Berk, "Cyclophilin A.," Circulation Journal, vol. 74, no. 11, pp. 2249-2256, 2010.

[12] S. K. Payeli, C. Schiene-Fischer, J. Steffel et al., "Cyclophilin A differentially activates monocytes and endothelial cells," Atherosclerosis, vol. 197, no. 2, pp. 564-571, 2008.

[13] N. N. Soe, M. Sowden, P. Baskaran et al., "Cyclophilin A is required for angiotensin II-induced p47phox translocation to caveolae in vascular smooth muscle cells," Arteriosclerosis Thrombosis and Vascular Biology, vol. 33, no. 9, pp. 21472153, 2013.

[14] H. Li, Y. Wang, D. Feng et al., "Alterations in the time course of expression of the Nox family in the brain in a rat experimental cerebral ischemia and reperfusion model: effects of melatonin," Journal of Pineal Research, vol. 57, no. 1, pp. 110-119, 2014.

[15] S. Matsushima, H. Tsutsui, and J. Sadoshima, "Physiological and pathological functions of NADPH oxidases during myocardial ischemia-reperfusion," Trends in Cardiovascular Medicine, vol. 24, no. 5, pp. 202-205, 2014.

[16] B. Lassègue, A. San Martín, and K. K. Griendling, "Biochemistry, physiology, and pathophysiology of NADPH oxidases in the cardiovascular system," Circulation Research, vol. 110, no. 10, pp. 1364-1390, 2012.

[17] K. Satoh, P. Nigro, T. Matoba et al., "Cyclophilin A enhances vascular oxidative stress and the development, of angiotensin II-induced aortic aneurysms," Nature Medicine, vol. 15, no. 6, pp. 649-656, 2009.

[18] K. J. Choi, Y. J. Piao, M. J. Lim et al., “Overexpressed cyclophilin A in cancer cells renders resistance to hypoxia- and cisplatin-induced cell death," Cancer Research, vol. 67, no. 8, pp. 3654-3662, 2007.

[19] K. Kim, I. K. Oh, K. S. Yoon, J. Ha, I. Kang, and W. Choe, "Antioxidant activity is required for the protective effects of cyclophilin A against oxidative stress," Molecular Medicine Reports, vol. 12, no. 1, pp. 712-718, 2015.

[20] S. Boulos, B. P. Meloni, P. G. Arthur, B. Majda, C. Bojarski, and N. W. Knuckey, "Evidence that intracellular cyclophilin $\mathrm{A}$ and cyclophilin A/CD147 receptor-mediated ERK1/2 signalling can protect neurons against in vitro oxidative and ischemic injury," Neurobiology of Disease, vol. 25, no. 1, pp. 54-64, 2007.

[21] Y. Seko, T. Fujimura, H. Taka, R. Mineki, K. Murayama, and R. Nagai, "Hypoxia followed by reoxygenation induces secretion of cyclophilin A from cultured rat cardiac myocytes," Biochemical and Biophysical Research Communications, vol. 317, no. 1, pp. 162-168, 2004.

[22] Z. Xue, W. Yuan, J. Li et al., "Cyclophilin A mediates the ox-LDL-induced activation and apoptosis of macrophages via autophagy," International Journal of Cardiology, vol. 230, pp. 142-148, 2017.

[23] Y. Wei, Y. Jinchuan, L. Yi, W. Jun, W. Zhongqun, and W. Cuiping, "Antiapoptotic and proapoptotic signaling of cyclophilin A in endothelial cells," Inflammation, vol. 36, no. 3, pp. 567-572, 2013.

[24] S. H. Kim, S. M. Lessner, Y. Sakurai, and Z. S. Galis, "Cyclophilin $\mathrm{A}$ as a novel biphasic mediator of endothelial activation and dysfunction," The American Journal of Pathology, vol. 164, no. 5, pp. 1567-1574, 2004.

[25] H. Shimokawa and K. Satoh, "Light and dark of reactive oxygen species for vascular function," Journal of Cardiovascular Pharmacology, vol. 65, no. 5, pp. 412-418, 2015.

[26] D. Burger, M. Turner, M. N. Munkonda, and R. M. Touyz, "Endothelial microparticle-derived reactive oxygen species: role in endothelial signaling and vascular function," Oxidative Medicine and Cellular Longevity, vol. 2016, no. 5, pp. 110, 2016.

[27] C. Meischl, P. A. J. Krijnen, J. A. Sipkens et al., "Ischemia induces nuclear NOX2 expression in cardiomyocytes and subsequently activates apoptosis," Apoptosis, vol. 11, no. 6, pp. 913-921, 2006.

[28] L. M. Khromykh, N. L. Kulikova, T. V. Anfalova et al., "Cyclophilin A produced by thymocytes regulates the migration of murine bone marrow cells," Cellular Immunology, vol. 249, no. 1, pp. 46-53, 2007.

[29] K. Satoh, T. Matoba, J. Suzuki et al., "Cyclophilin A mediates vascular remodeling by promoting inflammation and vascular smooth muscle cell proliferation," Circulation, vol. 117, no. 24, pp. 3088-3098, 2008.

[30] W. Yuan, H. Ge, and B. He, "Pro-inflammatory activities induced by CyPA-EMMPRIN interaction in monocytes," Atherosclerosis, vol. 213, no. 2, pp. 415-421, 2010.

[31] K. Satoh, P. Nigro, A. Zeidan et al., "Cyclophilin A promotes cardiac hypertrophy in apolipoprotein E-deficient mice," Arteriosclerosis Thrombosis and Vascular Biology, vol. 31, no. 5, pp. 1116-1123, 2011.

[32] F. Hong, J. Lee, J.-W. Song et al., "Cyclosporin A blocks muscle differentiation by inducing oxidative stress and inhibiting the peptidyl-prolyl-cis-trans isomerase activity of cyclophilin A: cyclophilin A protects myoblasts from cyclosporin Ainduced cytotoxicity," The FASEB Journal, vol. 16, no. 12, pp. 1633-1635, 2002.

[33] K. Satoh, Y. Fukumoto, K. Sugimura et al., “Abstract 281: cyclophilin A is a novel biomarker for oxidative stress and atherosclerotic diseases," Arteriosclerosis, Thrombosis, and Vascular Biology, vol. 33, no. 1, article A281, 2018. 


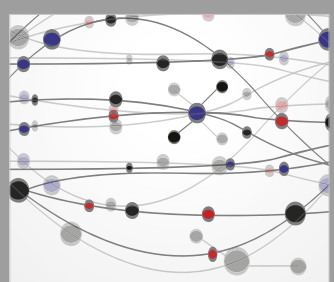

The Scientific World Journal
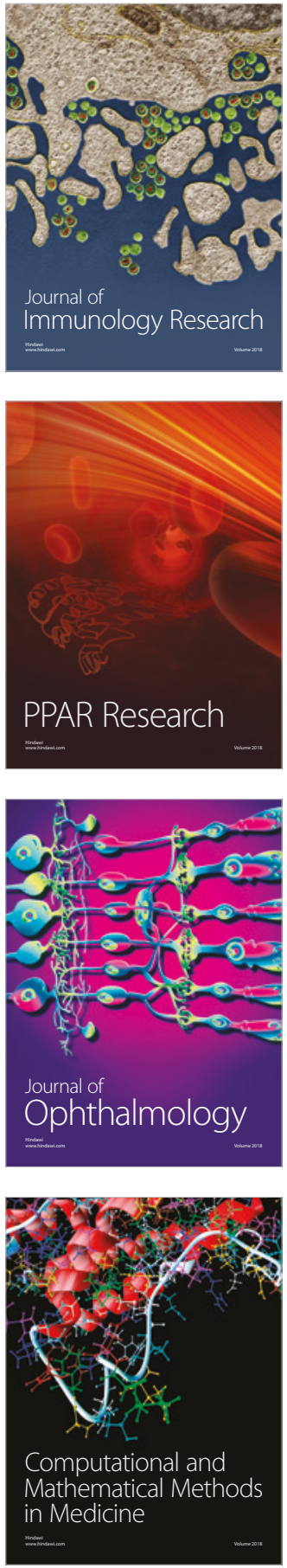

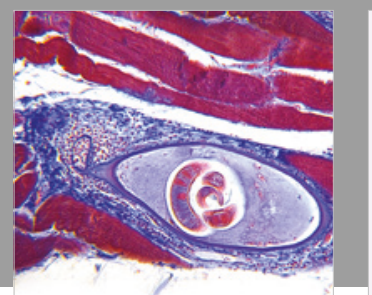

Gastroenterology Research and Practice

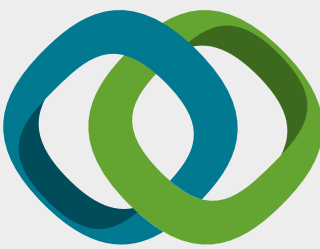

\section{Hindawi}

Submit your manuscripts at

www.hindawi.com
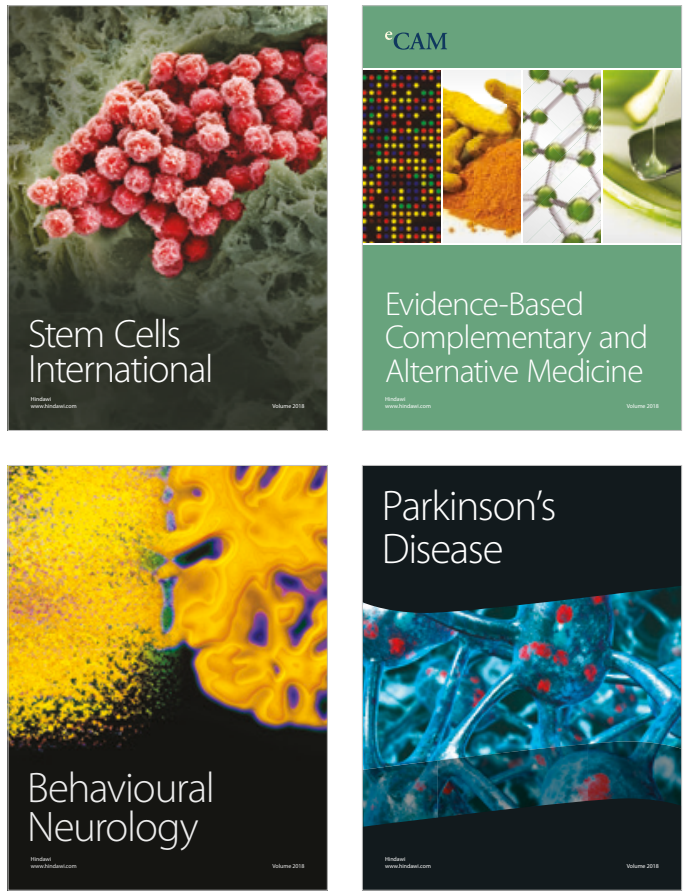

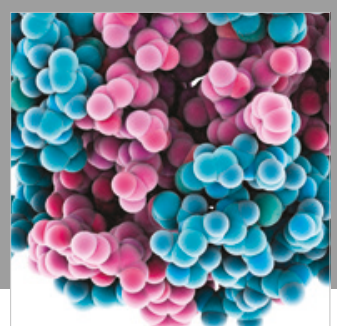

ournal of

Diabetes Research

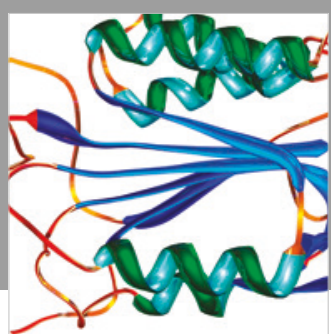

Disease Markers
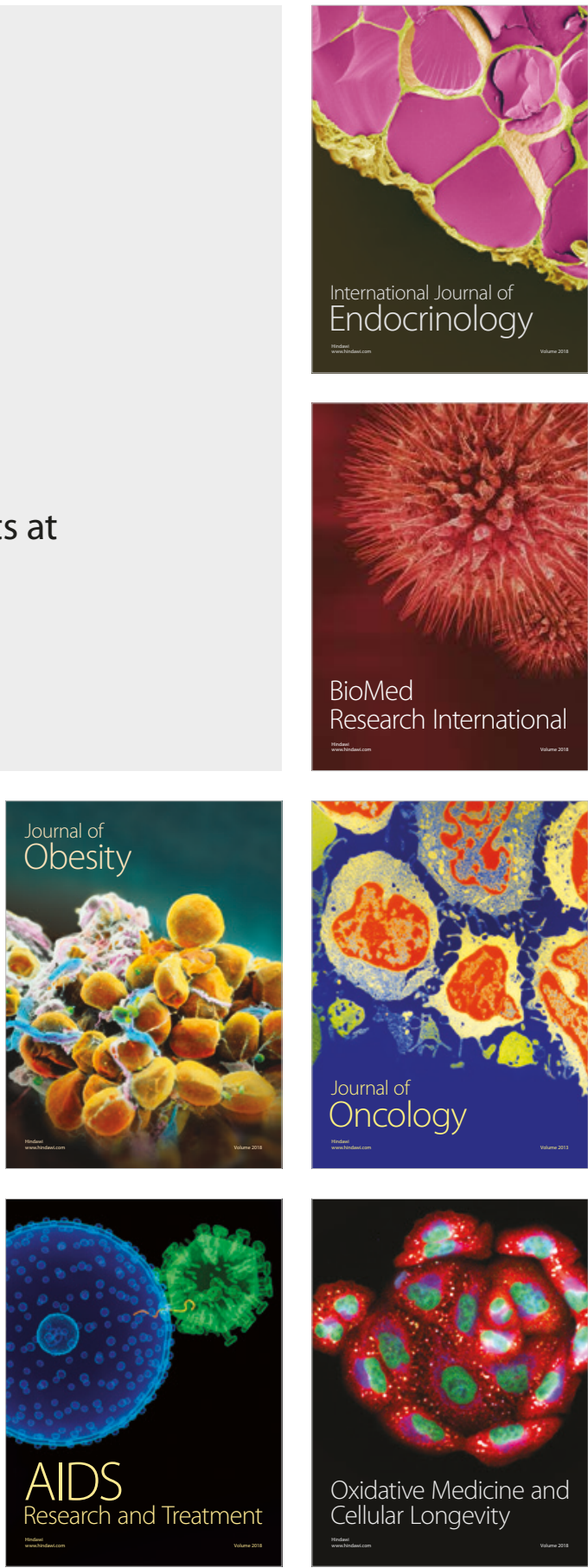